\section{Extremely Rare Anomaly of Native \\ Coronary Artery Bypass From Left Internal Thoracic Artery Compensating for Hypoplastic Coronary Arteries}

Tatsuro Yamazaki, MD;

Takatsugu Kajiyama, MD, PhD;

Hiroyuki Takaoka, MD, PhD;

Yoshio Kobayashi, MD, PhD

A 58-year-old-woman underwent computed tomography $(\mathrm{CT})$ after recovering from congestive heart failure. $\mathrm{CT}$ revealed a branch of the left internal thoracic artery (LITA) supplied the left ventricular (LV) myocardium (LVM), compensating for hypoplastic coronary arteries (Figure A). A persistent left superior vena cava and ventricular septal defect were also detected (Figure A,B). Invasive angiography revealed that the native branch of the LITA supplied the apex and inferior wall of the LVM (Figure C, Supplementary Movie). Linear late iodinate enhancement was detected in the intraventricular septum (Figure D). LITA anomalies are found in almost 30\% of candidates for coronary artery bypass grafting, and the largest number of them are abnormalities of origin. ${ }^{1}$ To our knowledge, an abnormal branch of the LITA supplying the LVM has not been reported previously.

\section{Funding}

This work was partially supported by the TSUCHIYA MEMORIAL MEDICAL FOUNDATION (grant no. J17KF00167).

\section{Disclosure}

Y.K. is a member of Circulation Journal's Editorial Team.

Received May 12, 2021; accepted May 13, 2021; J-STAGE Advance Publication released online June 26, 2021 Time for primary review: 1 day

Department of Cardiovascular Medicine (T.Y., H.T., Y.K.), Department of Advanced Cardiorhythm Therapeutics (T.K.), Chiba University Graduate School of Medicine, Chiba, Japan

Mailing address: Hiroyuki Takaoka, MD, PhD, Department of Cardiovascular Medicine, Chiba University Graduate School of Medicine, 1-8-1 Inohana, Chuo-ku, Chiba 260-8670, Japan. E-mail: tapy21century@yahoo.co.jp

All rights are reserved to the Japanese Circulation Society.

For permissions, please e-mail: cj@j-circ.or.jp ISSN-1346-9843

\section{Reference}

1. Bauer EP, Bino MC, von Segesser LK, Laske A, Turina MI. Internal mammary artery anomalies. Thorac Cardiovasc Surg 1990; 38: $312-315$.

\section{Supplementary Files}

Supplementary Movie. Invasive coronary angiography revealed that the native branch of the LITA supplied the apex and inferior wall of the LVM.

Please find supplementary file(s);

http://dx.doi.org/10.1253/circj.CJ-21-0447

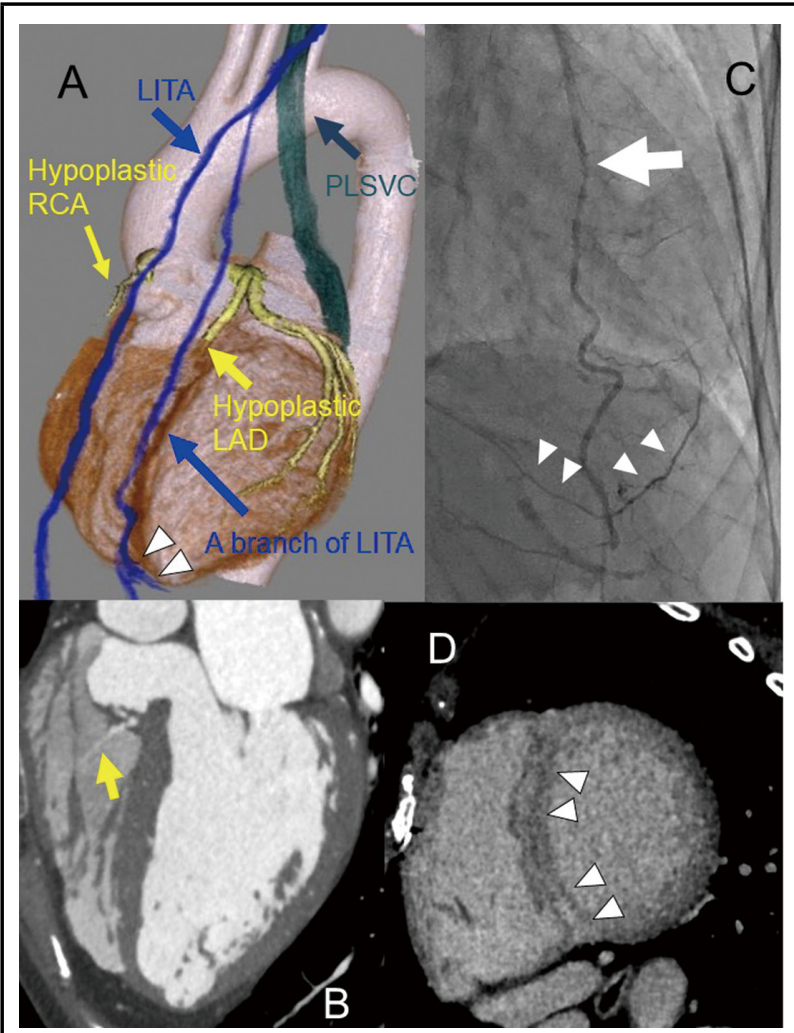

Figure. Computed tomography (CT) shows the hypoplastic left anterior descending (LAD) artery and right coronary artery (RCA) (A). A branch of the left internal thoracic artery (LITA) supplies the apex and inferior wall of the left ventricular (LV) myocardium (LVM) (A). A persistent left superior vena cava (PLSVC) (A) and shunt flow of a ventricular septal defect were also detected on CT (B, yellow arrow). Invasive angiography revealed that a native branch of the LITA supplied the apex and inferior wall of the LVM (C, white arrow and triangles, Supplementary Movie). Linear late iodinate enhancement was detected in the intraventricular septum (D, white triangles). 